\title{
Personal characteristics of extremist youth
}

\section{Eugenia P. Pchelkina,Tatyana N. Razuvaeva, Svetlana N. Pitka, Elena V. Kozhevnikova, and Svetlana V. Hashaeva}

Department of General and Clinical Psychology for the Faculty of Psychology and Department of Sociology and Organization of Work with Youth of the Belgorod State National Research University (NRU «BeISU»)

\section{Introduction}

The study was aerobatic in nature. His goal was to reveal some of the personal qualities of young people, former members of terrorist groups.

The threat of terrorism remains one of the unsolved problems of modern society. In the very phenomenon of extremism and terrorism, metamorphoses occur, changes in its forms and content. Now there are no longer loners, but large and well-organized structures. We can say about the institutionalization of relevant practices with a well-established system of recruitment, training and socialization of new members. In addition, the object of attacks are not any significant person, and often just random people. The goal is changing - not to eliminate the "interfering" person, but to declare yourself and your requirements as loudly as possible and illustrate this statement with as many victims as possible. Each act of terrorism becomes a kind of performance, and from this side is carefully prepared.

Terrorism itself begins to have the character of association by type of state and even intergovernmental organizations with which it opposes (A.V. Klyuev, D.V. Olshansky and V.V. Ustinov). This is a kind of anti-state and alternative to the state phenomenon as its shadow or distorted mirror representation. This is attractive for many young people who could not successfully realize themselves in society.
In modern terrorism there is a more global problem - the problem of manipulating the value orientations of various cultures, the value confrontation of the individual and culture, the skillful use of the opposition "I and the Other" by terrorists (N.L. Vinogradova, I.L. Pashkevich, V.B. Ustyantsev).

To study the phenomenon, using the methods of observation, especially experiment, in most cases is not possible. The retrospective approach used does not provide a definitive understanding of the mechanisms for disseminating these practices.

\section{Methods}

We conducted the study on a sample of prisoners from four prisons in Kurdistan, the former participants of terrorist groups in 2015 (B.Z. Nanakali, the scientific leadership - E.P. Pchelkina). The sample consisted of 30 men aged 18 to 45 years old who are serving sentences for participating in the terrorist attacks in the prisons of Kurdistan "Sousse" the Iraqi correctional system.

To study the value orientations, we used the method of E.B. Fantalova, suicidal risk was studied using the method of A.A. Kucher, V.P. Kostyukevich and tests V.B. Nikishina, aggressiveness - test L.G. Pochebut, selfattitude - methods V.V. Stolin, whose modification we used to study attitudes towards others, studied attitudes towards terrorism using the author's questionnaire.

\section{Results}

The analysis of the value hierarchy of prisoners, former members of extremist and terrorist groups, showed contradictory results: the presence of destructive values along with creative ones, the presence of conflict in almost all significant values, except for material well-being and public life, in general, pessimistic attitude towards oneself

Life as the most capacious value does not represent significance relative to the value of death that is more important for terrorists. The value of life, moreover, is also more internally conflicting. Terrorists perceive it as almost completely impossible to implement.

Love for the father was not included in the list of 30 significant values at all. Moreover, love for the mother came out on top.

The same applies to the values of studies, family, freedom and love for children. They are not rejected, they are very significant, almost as well as the values of violence, physical strength and death. It is possible that the terrorist group to some extent replaces the person's mother, family, parent-child relationships, socialization and study takes place there.

Values to be a winner, like-minded people, idleness, sports and loneliness turned out to be highly accessible, but completely irrelevant for the respondents.

The study showed a tendency among respondents to suicide, as well as a negative background of the emotional state, pessimism of mood. The most stressful factors were money, the problem of relationships with others, unhappy love, a sense of inferiority, inferiority and deformity, loss of the meaning o life, the problem of choosing a life path, as well as the problem of alcohol and drugs.
They did not differ from ordinary people in the level of aggressiveness. The very nature of activity determined their aggression.

Overall, they highly appreciated themselves due to self-confidence, attitude towards themselves as a source of activity, but at the same time also due to internal conflicts, selfincrimination. However, we see an underestimation of themselves in comparison with others, although at first glance, their attitude toward themselves looks quite optimistic.

According to

socio-demographic Acsics the respondents did not have bright differences from ordinary people. All respondents were young, educated men professing Islam. The respondents were critical of the phenomenon of terrorism, agreed to the most stringent measures in relation to its participants, but also showed answers loyal to the authorities, social desirability, high rationality, pessimism, and negative attitude toward themselves. They presented themselves, as victims of coercion, fighters for the idea, did not deny receiving good pay, as well as mental abnormalities.

Thus, the results were inconsistent. Prisoners, former members of terrorist groups, had undifferentiated values, combined constructive with destructive ones. They had an intrapersonal value conflict for practically all significant values, except for material wellbeing and social life, a gap of high level of significant values and low availability of their realization. They also had a suicidal risk at the tendency level; average level of aggressiveness. Their attitude to themselves combined self-confidence and independence with a penchant for self-accusation. They believed that others treat them without positive feelings. Their attitude towards terrorism was also controversial (the justification is closely related to the prosecution) 